\title{
Data rescue initiatives: bringing historical climate data into the 21st century
}

\author{
Manola Brunet ${ }^{1,2, *}$, Phil Jones ${ }^{2}$ \\ ${ }^{1}$ Centre for Climate Change, Geography Dept., University Rovira i Virgili, Av. Catalunya, 35, Tarragona 43071, Spain \\ ${ }^{2}$ Climatic Research Unit, School of Environmental Sciences, University of East Anglia, Norwich NR4 7TJ, UK
}

\begin{abstract}
The currently limited availability of long and high-quality surface instrumental climate records continues to hamper our ability to carry out more robust assessments of the climate. Such assessments are needed to better understand, detect, predict and respond to global climate variability and change. Despite the wealthy heritage of past climate data and recent efforts to improve data availability and accessibility, much more surface data could be digitised. Additionally, some long records are not of the quality needed for more confidently supporting any climate assessment, service, or application. The present paper discusses the usefulness of undertaking integrated data rescue (DARE) activities by showing several climate assessments as examples. It describes emerging DARE activities worldwide, with a focus on the World Meteorological Organization Mediterranean Data Rescue (MEDARE) and the Atmospheric Circulation Reconstructions over the Earth (ACRE) initiatives to assess the benefits historical instrumental climate data can bring to studies of climate variability and change that consider the 21 st century.
\end{abstract}

KEY WORDS: Climate change - Instrumental period - Climate assessments - Data rescue . Integrated DARE . High-quality climate data development . WMO/MEDARE initiative . ACRE initiative

Resale or republication not permitted without written consent of the publisher

\section{INTRODUCTION}

Our atmosphere has been regularly and conscientiously monitored worldwide since the mid-19th century and even earlier over some other parts of the world (e.g. Europe) by national meteorological services (NMSs), as well as scientific societies, medical doctors and theologians, particularly the Jesuit Company (Udías 2003), that pre-date the founding of NMSs. Nevertheless, the current availability and accessibility of long-term and high-quality instrumental climate data are still very limited and are hampering our ability to carry out more reliable and long-term climate assessments to better understand, detect, predict and respond to global climate variability and change (Trenberth et al. 2007). The current availability of digital climate data (particularly daily series, which enable extremes to be assessed) is often restricted to the second half of the 20th century over many parts of the world. There are some exceptions (e.g. several loca- tions in Europe), where some of the longest climate time series have been developed and are already available. However, for many regions/countries, the availability of digital climate data is restricted to the last third of the 20th century, despite much recent effort by NMSs, international bodies/expert teams and other research centres/organisations in attempting to improve data availability (see Peterson \& Manton 2008 for an overview of the activities carried out by the WMO-CCl/WCRP-CLIVAR/UNESCO-JCOMM ETC$\mathrm{CDI}^{\mathbf{1}}$ ). This spatially and temporally limited coverage

\footnotetext{
${ }^{1}$ The joint World Meteorological Organization (WMO) Commission for Climatology (CCl)/World Climate Research Programme (WCRP) project on climate variability and predictability (CLIVAR)/joint WMO-Intergovernmental Oceanographic Commission of the United National Educational, Scientific and Cultural Organization (UNESCO) Technical Commission for Oceanography and Marine Meteorology (JCOMM) expert team on climate change detection and indices (ETCCDI)
} 
of currently available digital climate data is obstructing our ability to better understand multi-decadal climate variability and its forcing factors at scales smaller than continental. Additionally, some of the available and accessible data do not reach the required standards of quality and homogeneity, making their usage doubtful for undertaking any climate analysis, applications, or services (e.g. Mestre 2008). It is widely known that raw digital climate data are subject to a wide range of errors, which can be introduced along the chain of collecting, digitising, processing, transferring, storing and transmitting the data; a demand is not being made to keep and store crucial data forever (Anonymous 2010). A wide set of procedures for quality controlling (QC) raw data have been developed, which are recommended by the World Meteorological Organization (WMO) and implemented or used by investigators to detect and flag potentially erroneous values in any dataset (e.g. Abbott 1986, Vose et al. 1992, Peterson et al. 1998b, Aguilar et al. 2003, Daly et al. 2004, Feng et al. 2004, Brunet et al. 2008, You et al. 2008, Sciuto et al. 2009). To move beyond the raw data, QC procedures are the first step in developing highquality climate datasets, although it is neither the only one nor the most important. Once a record is reasonably free of errant individual values, e.g. it is quality controlled, the time series has to be subjected to further tests (referred in climatology as homogeneity testing) to show that its variability and change only result from the forcing exerted by weather and climate factors and are not the result of artefacts, such as changes in instrumentation, observational practices, relocation of the observatory, alterations in its surrounding, or such that can induce break points in time series homogeneity. Homogeneity testing and homogenisation methods have to be employed to ensure that any time series is reasonably free or not affected by spurious or sudden changes (artificial break points). Sometimes these abrupt shifts or gradual trends are of similar magnitude to the climatic signals that are being looked for (for reviews and assessments of the different kinds of homogeneity tests and homogenisation procedures available see, e.g., Szalai \& Szentimrey 1996, Peterson et al. 1998a, Aguilar et al. 2003, Mestre 2008). Thus, the second and most important step is to ensure that a time series is homogeneous by subjecting it to any of the available homogeneity detection methods. There will always be a small group working to refine the methods that might be used (attempting to improve detection of all break points), but the key is not to wait until there is a best method, or to choose the best method at present, but rather to undertake homogeneity testing. When homogeneity testing reveals problems or issues with a time series, it is important to move on to the next step and adjust the series if necessary and keep a record of what has been undertaken and why. The adjusted series can then be used for a whole range of climate assessments. Keeping a record of what has been done enables others to come back later if homogeneity test methods are improved.

Integrated data rescue (DARE) initiatives initially require the gathering of climate data held in fragile media (e.g. paper format, perishable imaging media) by applying a whole set of procedures for locating the data and efficiently transferring it into digital format. The digitisation process, however, has to be carefully done, as it is vital to digitise the exact values reported in the original source, even when obvious errors can be detected at this stage. The original digitised data, therefore, have to be archived exactly as they are shown in the original source. At the same time, it is advisable to keep images of the original source to and link them to the digitised data to allow other researchers to verify the data for accuracy. The second stage is the quality control of the data and, finally, the homogeneity testing and homogenisation procedures, if required. Although the final step is the most important for the use of climate data, nothing will improve until the first step is undertaken. In the present paper, using several case studies, we document a number of the potential benefits of undertaking integrated DARE activities, describe some of the emerging and ongoing DARE initiatives that are improving the availability and accessibility to historical climate data. The rationale and benefits of undertaking integrated DARE activities for enhancing climate assessments are shown by means of several examples in Section 2. The third section provides a general framework for ongoing and emerging international integrated DARE projects and initiatives; specifically, we address the WMO/ Mediterranean Data Rescue (MEDARE) initiative and the Atmospheric Circulation Reconstructions over the Earth (ACRE) project. The last section is a summary and provides an outlook into the future along with some recommendations.

\section{THE RATIONALE: WHY IS UNDERTAKING DARE ACTIVITIES BENEFICIAL?}

High-quality, high-resolution (both spatial and temporal) and long-term climate data are of paramount importance for more confidently undertaking a wide range of climate assessments, services and applications. Among the uses are (1) regional climate change detection/attribution studies (assimilating observational and modelling activities), (2) the assessment and calibration of climate proxy records, (3) the calibration of satellite data and (4) the generation of climate change scenarios or climate reanalyses products. For instance, 
if we know which climate models are more accurate, we can predict the future more exactly and with more confidence. To evaluate which models perform better and reproduce climate variability more exactly, we need to know more about the climate of the last 1000 yr. For a better understanding of the climate variations during the last millennium, we first need to better understand the instrumental climate (over the past $200 \mathrm{yr}$ ), as this will allow a more precise assessment of the climate of the last $1000 \mathrm{yr}$, including its forcing factors. Therefore, the currently limited availability of good and long historical weather observations is constraining our knowledge of both the past and future climates (Brohan 2009). In short, improved climate data availability would enable a better understanding, detection and prediction of global climate variability and change. Extending back in time, climatic time series bring a wide number of scientific benefits, either to the NMSs for improving their data and products or to the climatological research community for making possible more robust climate assessments (Jones 2008a). One of the clearest benefits is that longer climate records make possible more extensive trend and other assessments, enabling recent climate data and extremes to be placed into a longer instrumental context. Fig. 1 shows annual temperature averages (as anomalies compared to the baseline period 1961-1990) for Fennoescandia, Central England and Central Europe, extending back to the late-18th century (Fennoescandia and Central Europe) and to the mid-17th century (Central England). Long time-series also enable the examination, among other aspects, of the climatic impact of volcanic eruptions, as has been undertaken by Jones et al. (2003). Also, recent extremes, such as the unprecedented heat wave that affected Europe in summer 2003 can be put into the studies, which can explore whether the recent trends or anomalous high or low averaged values shown in the time series are or are not unprecedented throughout their corresponding instrumental record. Schär et al. (2004) also explored the unprecedented heat wave recorded over Europe in 2003. Fig. 4 (adapted from Schär et al. 2004) shows the distribution of monthly

\section{Annual temperature anomaly w.r.t. 1961-90}

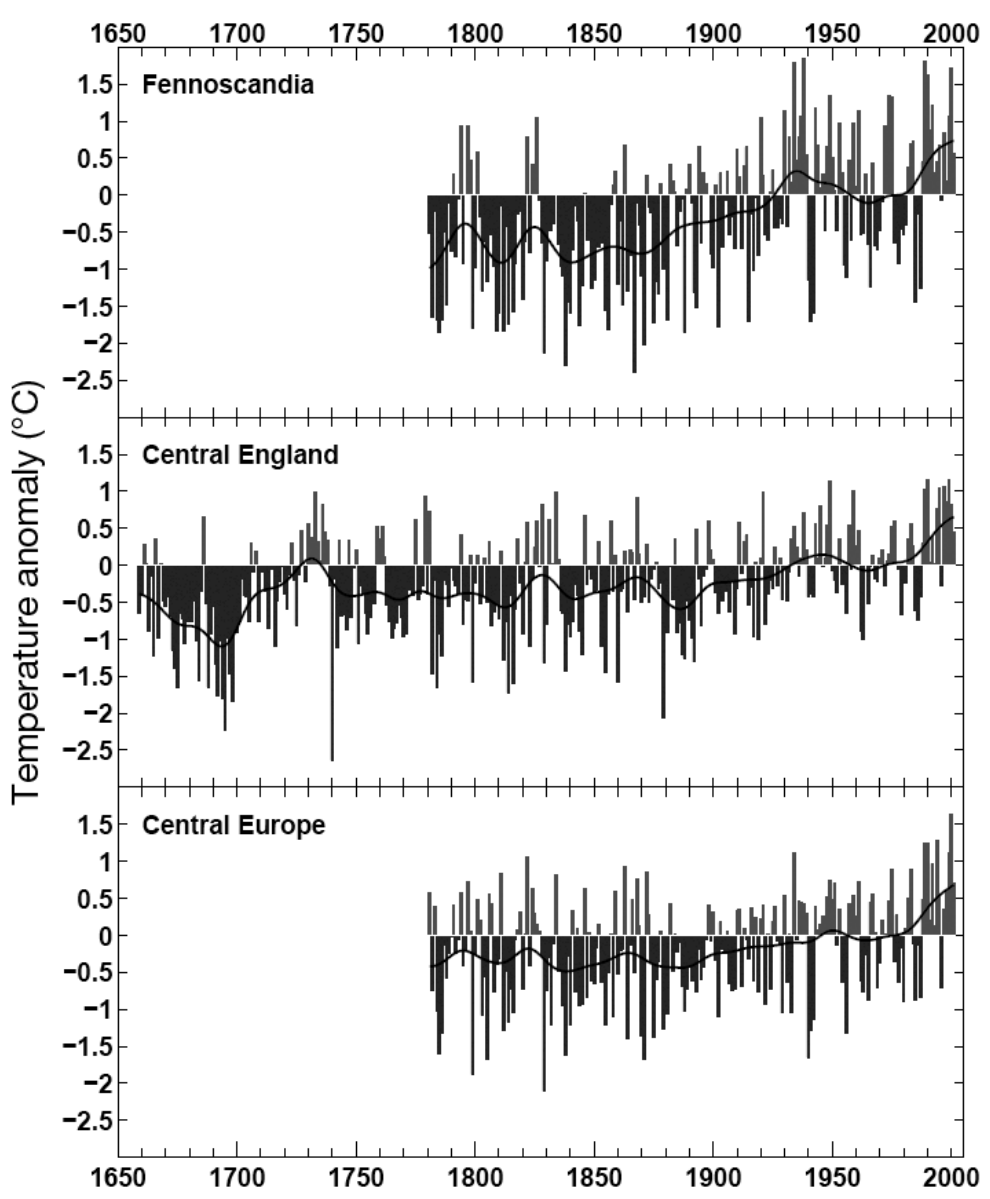

Fig. 1. Annually averaged temperature anomalies (bars), relative to the 1961-1990 baseline period, for Fennoscandia, Central England and Central Europe. Solid line: 20 yr Gaussian smoothing filter; w.r.t.: with relation to. Adapted from Jones (2008a) context of the longest instrumental records. Fig. 2 (adapted from Trenberth et al. 2007) and Fig. 3 (adapted from Brunet et al. 2007) illustrate areaaveraged summer (June-August) temperatures over Central Europe and mainland Spain for the 1780-2005 and 1850-2005 periods, respectively, exemplifying the unusualness of the 2003 summer temperature values in these long records. Such long time series make possible enhanced regional climate change detection and attribution

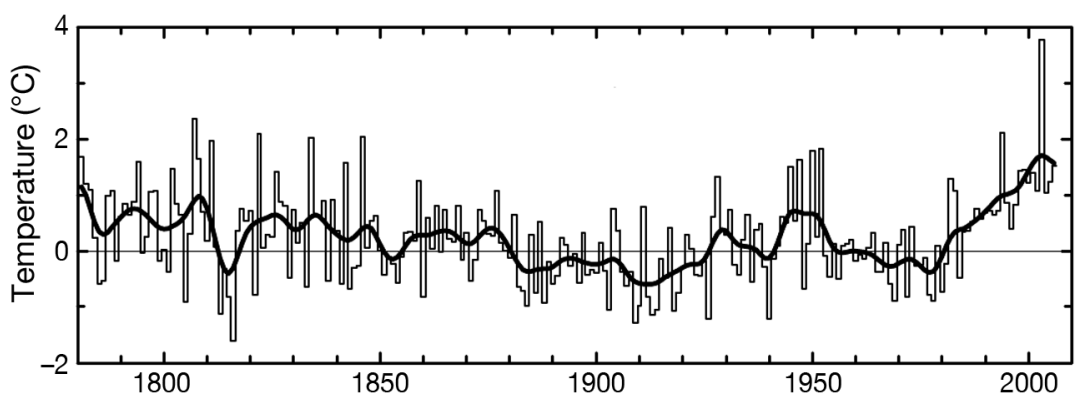

Fig. 2. Summer averaged (June-August) temperature anomalies (thin line) for Central Europe back to 1780, relative to the 1961-1990 baseline period. Thick line: 10 yr Gaussian smoothing filter. Adapted from Trenberth et al. (2007) 


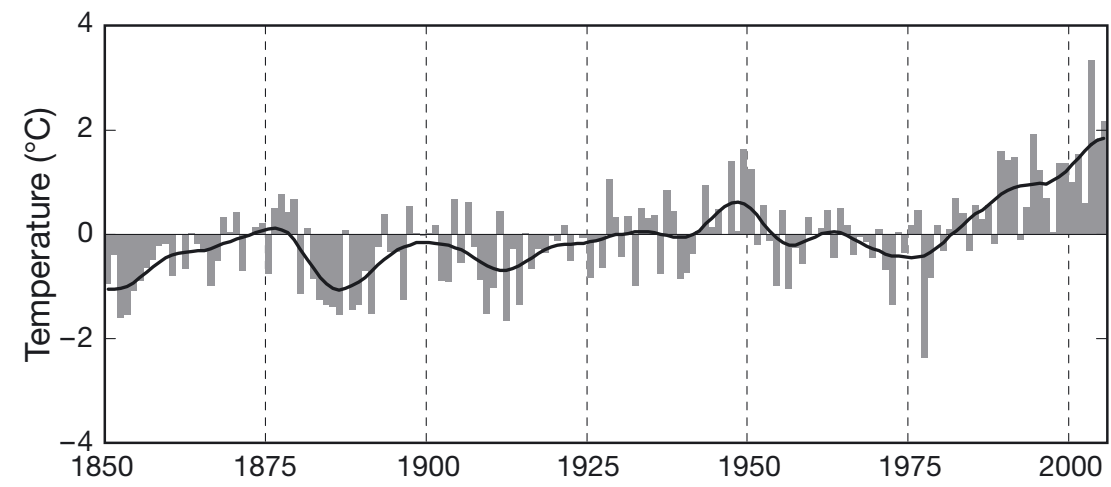

Fig. 3. Summer averaged (June-August) temperature anomalies (bars) for mainland Spain back to 1850, relative to the 1961-1990 baseline period. Solid line: $13 \mathrm{yr}$ Gaussian smoothing filter. Adapted from Brunet et al. (2007)
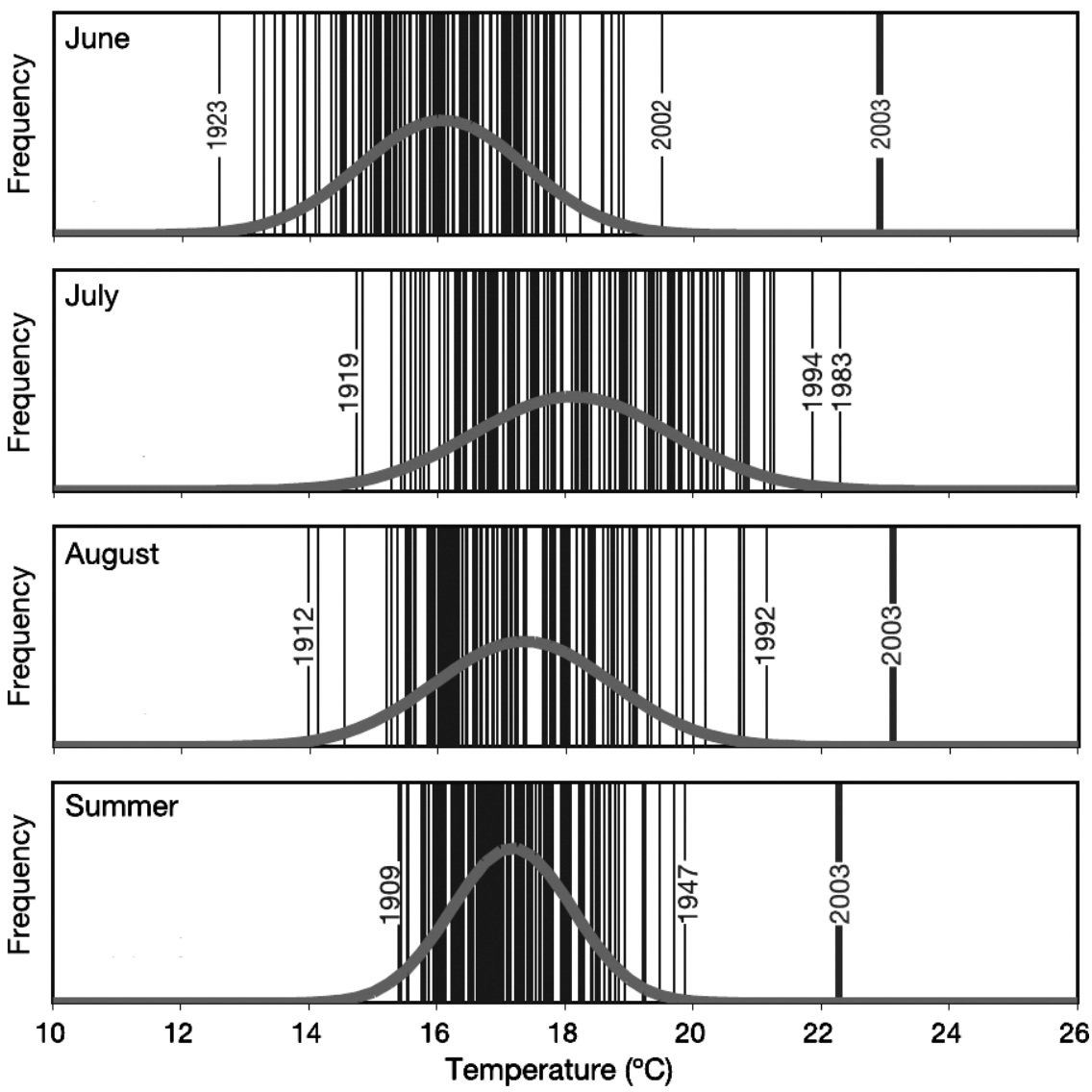

Fig. 4. Distribution of Swiss monthly and summer (June, July and August) averaged temperatures for 1864-2003 (thick grey curve). Individual monthly and summer averages are shown by the vertical black lines. Adapted from Schär et al. (2004)

and seasonal summer temperature averages for the period 1864-2003 over Switzerland. In these plots, it can be seen that the unusually high values recorded during June and August and during the whole summer of 2003 were far away from the average distribution, and the standard deviation was \pm 5.4 from the summer mean. As summarised by Schär et al. (2004), the Euro- pean summer climate might see a marked rise in year-to-year variability in response to greenhouse gas forcing, which might explain the unprecedented European summer of 2003. In this regard, Stott et al. (2004), using observed summer temperatures over Europe for the period 1990-2003 and modelled temperatures from 4 HadCM3 simulations (including anthropogenic and natural forcings to project summer temperature change into the future; Fig. 5), showed that the unprecedented European summer in 2003 could be normal conditions for the 2040s, but the latter could also represent cold conditions 2 decades later (for 2060s). These authors concluded that it is very likely (confidence interval $>90 \%$ ) that anthropogenic influences have at least doubled the risk of such heat wave occurrences. Long term and high-quality climate records from climate proxy evidence are also indispensable for developing climate reconstructions longer than the instrumental record. such as those resulting from analysing geophysical (e.g. ice cores), biological (e.g. tree-rings, corals), or historical (e.g. rogation ceremonies documentation) archives. Proxy data can further extend back in time climatic reconstructions and thus extend our knowledge about climate variability over longer than decadal (e.g. multidecadal, centennial and millennial) time scales. In some regions like Europe, North America and eastern Asia, where both long instrumental and proxy evidence records exist or can be developed, it is possible to assess the quality of the reconstructions by using the longest instrumental records to constrain and calibrate the proxy evidence (Jones 2008b). The 2 plots in Fig. 6 show 2 cases of using long-term instrumental data to assess and calibrate historical (ice breakup dates) and biological (tree-ring) proxy series. Fig. 6a shows a composite of monthly (April-May) temperature records developed for northern Sweden (Tornedalen) for the 1802-2002 period by Klingbjer \& Moberg (2003) and ice breakup dates in spring (April-May) on the Tornio River, and illustrates the co-variations between 


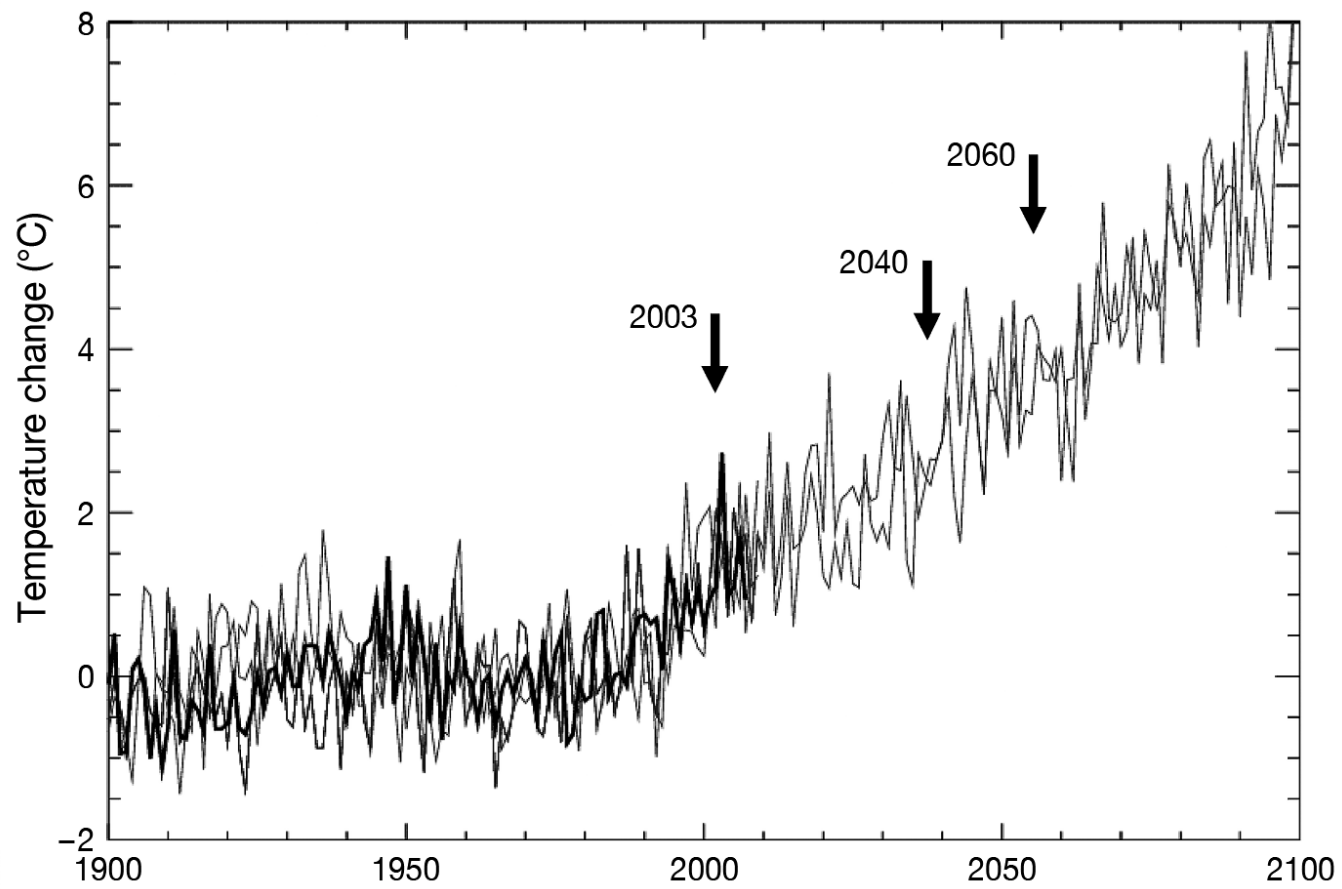

Fig. 5. Observed summer averaged (June-August) temperature anomalies (thick black line), relative to the 1961-1990 baseline period and 2 HadCM3 temperature projections to 2100 for Europe (thin lines). Adapted from Brohan (2009) based on Stott et al. (2004)

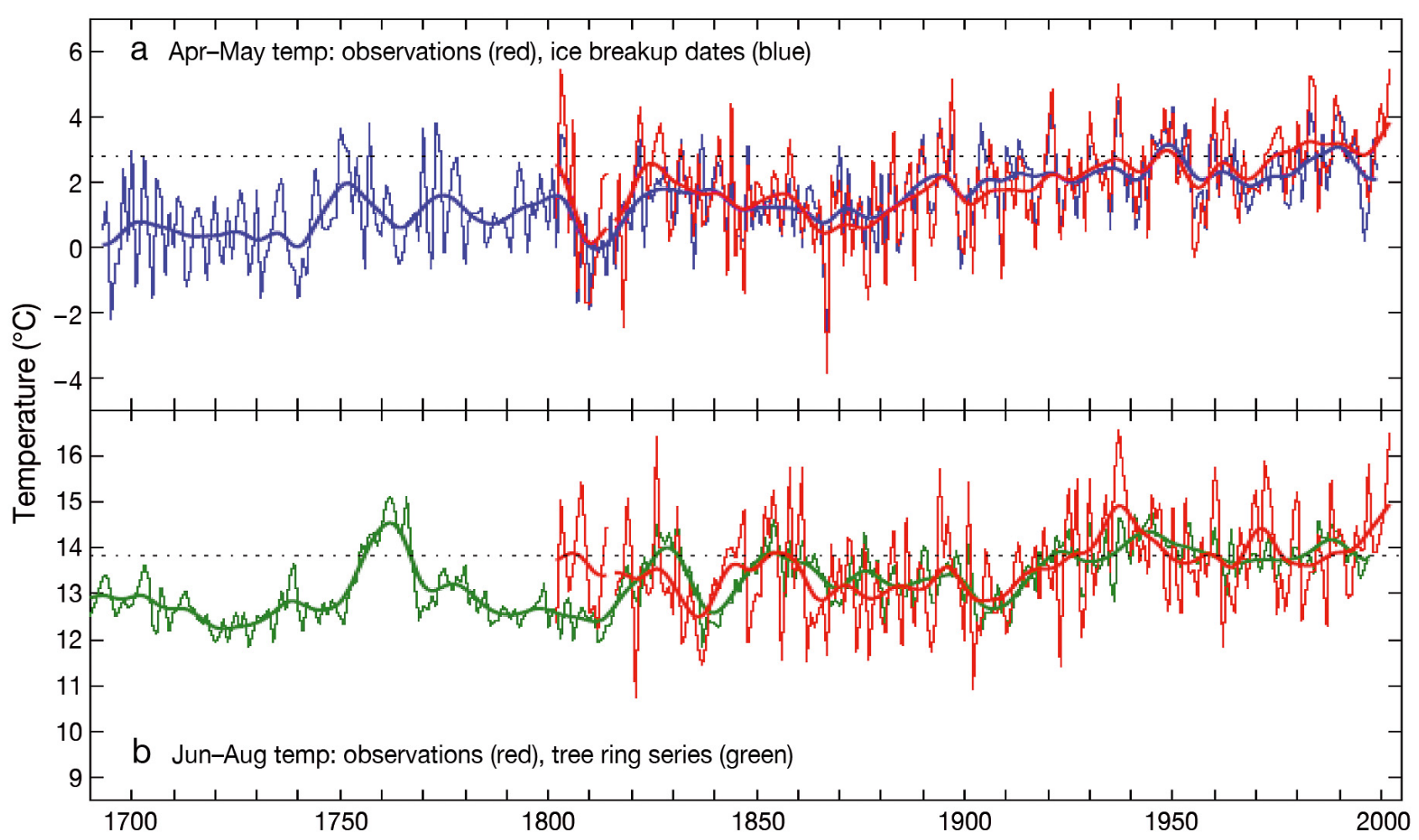

Fig. 6. Assessment of long-term proxy records, using instrumental climate data. (a) April-May averaged instrumental temperature (red) and calibrated temperatures based on ice break-up dates (blue) for the Tornio River (Fennoscandia). (b) Summer averaged (June-August) instrumental temperatures (red) and calibrated temperatures based on tree-ring width and density records (green) near Lake Torneträsk (northern Sweden). Dashed lines: 1961-1990 means 
instrumental and proxy records and the potential for further extending the instrumental records back in time from the ice breakup dates. Fig. 6b shows the summer (June-August) temperature record (18002002, again from Klingbjer \& Moberg 2003) and a treering series (from $\sim 5000 \mathrm{BC}$ to the near present) from measurements taken near Lake Torneträsk in northern Sweden (see e.g. Briffa 2000). In both plots good agreement is shown between instrumental and proxy series at the interannual, decadal and multi-decadal time scales. Using these examples, the scientific importance of rescuing and developing long and high-quality climate records should be clear. They bring to the scientific community and to society at large priceless information about our climate. They help us to enhance our knowledge on instrumental climate variability and change, as well as their forcing factors; to place any changes in the mean or extreme states of the climate in a larger context, and they enable an extended calibration of proxy records from natural and documentary archives. These extensions will also facilitate climate change detection and attribution analysis and allow us to validate climate model output (both general climate models and regional climate models), as suggested by Jones (2008c).

\section{EMERGING AND ONGOING INTERNATIONAL DARE PROJECTS}

Since the early 1980 s, there has been rising awareness among international bodies (e.g. WMO, Global Climate Observing System [GCOS]), NMSs, research centres and interested individuals on the key and urgent need to recover and transfer into digital format historical weather observations held in perishable media in order to enable their treatment. While it is not intended to make a detailed summary of such DARE activities, it is worth mentioning the WMO guide and recommendations to its associated state members/ NMSs, which have been published through the World Climate Data Monitoring Program's (WCDMP) series publications (e.g. WMO 1990, 1996, 2008, Aguilar et al. 2003, Tan et al. 2004, Brunet et al. 2008, Brunet \& Kuglitsch 2008), and the efforts of the GCOS to improve climate data availability and standards in support of climate variability and change monitoring and detection studies (GCOS 1996, 1997, 1998, 2001, 2002, 2006).

It is also important to highlight the efforts undertaken by NMSs elsewhere to digitise and quality control their holdings. A good example the German NMS (Deutscher Wetterdienst; DWD) activities in DARE through its KLIDADIGI project, which is aimed at digitising all historical data from German land sta- tions, or the 'overseas' project, focused on digitising surface climate data from overseas stations (Gloeden 2009). Also, there have been remarkable efforts made by the Zentralanstalt für Meteorologie und Geodynamik (ZAMG) through previous and ongoing HISTALP projects digitising, quality controlling and homogenising $>500$ climate time series (e.g. temperature, precipitation, cloudiness, air pressure, bright sunshine, relative humidity, vapour pressure) from 200 observation sites (Auer et al. 2007, Böhm et al. 2009) in the greater Alpine region.

There are also remarkable past and ongoing efforts being undertaken by research centres and investigators elsewhere, in order to recover and develop longterm climate time series as a component of funded research projects. For example, on the European scale, the EU-funded project EMULATE ${ }^{2}$, developed the EMULATE sea level pressure (EMSLP) daily dataset (Ansell et al. 2006) and the EMULATE daily temperature and precipitation dataset (Moberg et al. 2006) for the period 1850-2003. These have enabled better analyses and a more exact understanding of atmospheric circulation anomalies and their influence on the European surface climate (e.g. Della-Marta et al. 2006, Philipp et al. 2007, Jacobeit et al. 2009). Also, the European Climate Assessment \& Dataset ${ }^{\underline{3}}$ project (ECA\&D; Klein-Tank et al. 2002a,b) has greatly contributed to increased daily temperature and precipitation data availability all over Europe and analysis of changes in climate extremes over this region (e.g. Klein Tank \& Können 2003, Haylock \& Goodess 2004, Moberg \& Jones 2005).

More recently, a number of international DARE initiatives have been emerging with a mission to improve both the availability and accessibility to long-term and high-quality climate records for some of the GCOS essential climate variables (ECVs), as well as capacitybuilding through integrated DARE bilateral and multilateral projects. The Dutch/Indonesian initiative to rescue, digitise and disseminate historical Indonesian climate data (DiDaH project Brandsma \& Van der Schrier 2009), is an example of successful bilateral collaboration, both in the development and dissemination of high-quality and long-term climate records and in capacity-building on DARE techniques and methods. Two international DARE initiatives, the WMO/MEDARE project and ACRE are discussed in the 2 following subsections.

\footnotetext{
2EMULATE: European and North Atlantic daily to multidecadal climate variability (www.cru.uea.ac.uk/cru/projects/ emulate)

${ }^{3}$ The ECA\&D project was initiated by the European climate support network (ECSN) and supported by the network of European meteorological services (EUMETNET). For further information see: http://ecad.knmi.nl/
} 


\subsection{WMO MEDARE initiative}

The WMO/MEDARE is a cooperative effort aimed at enhancing surface climate data availability over the Greater Mediterranean Region (GMR), initiated under the auspices of the WMO and endorsed by its Executive Council at its 60th session in 2008. MEDARE brings together scientists from most of the NMSs in the GMR, universities and research centres worldwide. Its main goal is to develop, consolidate and improve surface climate data and metadata rescue activities across the GMR, but also to foster capacity building activities in the techniques and procedures required in undertaking integrated DARE activities, including the development of high-quality and homogeneous climate datasets. MEDARE key components are collaboration, partnership, information sharing, multilateral DARE projects and networking, as shown in the MEDARE terms of reference (www.omm.urv.cat/MEDARE/termsof-reference.html).

MEDARE's, long-term goal, therefore, is to develop a comprehensive high-quality, high-resolution time series of instrumental climate data for the GMR, with a focus on the ECVs of the GCOS, which will support the Mediterranean countries and this important region (Giorgi 2006, IPCC 2007) in better monitoring, detection and prediction of climate variability and change at regional and national levels. Thus, it will allow the GMR countries to develop more robust strategies for managing climate-related risks and to generate climate change scenarios and impact sector models to define/adopt better strategies for adapting to climate change-related impacts. Other MEDARE objectives are to undertake multilateral integrated DARE projects, targeting the development of longterm, high-quality high-resolution time series, with a focus on the main ECVs and on capacity building and training in DARE and homogenisation techniques and procedures. MEDARE is currently composed of the bulk of the Mediterranean NMSs (24), supported by 11 research centres and about 100 scientists (www. omm.urv.cat/MEDARE/medare-community.html), besides being open to any organisation or individual interested in these research fields. The initiative is organised into 4 working groups (WGs; www.omm. urv.cat/MEDARE/mi-working-groups.html): WG1 develops inventories, assessing and approaching archival sources and holders and is composed of 21 experts; WG2 is involved in DARE techniques and procedures, including digitisation (16 experts); WG3 works on the best approaches to quality controlling and homogenising specific climate variables (23 members); and WG4 is involved in promotional activities, making MEDARE known to the wider scientific and other communities (14 experts).
Although this WMO initiative is currently being implemented, the MEDARE Community has been active in several fields since its inception. A number of activities have been carried out in order to develop the MEDARE implementation plan (IP; see Jones 2008c for an overview of the MEDARE IP). A web-based and password-protected metadata web-site and data portal (http://app.omm.urv.cat/urv/) have been developed (1) to construct an inventory of the longest and most important national climate records available, both in digital and other formats (Mediterranean NMS archives and other sources/holders of data), and to archive, access and disseminate the metadata collected; and (2) as an integrated on-line infrastructure for data entering and dissemination. Also, the MEDARE web-site has been implemented (www.omm. urv.cat/MEDARE/index.html) as a tool for linking the MEDARE community, its external contributors and end-users, publicising and raising awareness on DARE needs and for documentation exchange.

Finally, the MEDARE community has been very active in organisational tasks and in publicising and raising awareness of the essential requirements of developing high-quality/high-resolution climate data, through discussions, documentation, meetings (organisation and attendance), and in producing posters, brochures and leaflets for distribution among stakeholders, policy-makers and the general public. Especially worthy of mention are the synergies fostered with other related initiatives (e.g. MedCLIVAR, ACRE) and international bodies (e.g. UNFCCC/SBSTA and GCOS), the publication of the first comprehensive overview of DARE benefits, current climate data availability over the GMR and the need for targeting DARE projects over the Mediterranean Basin (Brunet \& Kuglitsch 2008), along with the organisation of 2 the MEDARE workshops and the attendance at many scientific conference or expert meetings elsewhere (Brunet 2009).

\subsection{The Atmospheric Circulation Reconstructions over the Earth (ACRE) initiative}

ACRE is an international joint initiative led by a consortium composed of the Queensland Climate Change Centre of Excellence (QCCCE) in Australia, the Met Office Hadley Centre in the United Kingdom, the United States National Oceanic and Atmospheric Administration (NOAA) Earth System Research Laboratory (ESRL), and the Cooperative Institute for Research in Environmental Sciences (CIRES) at the University of Colorado. Its main goal is facilitating the recovery of historical instrumental surface terrestrial and marine meteorological observations recorded world- 


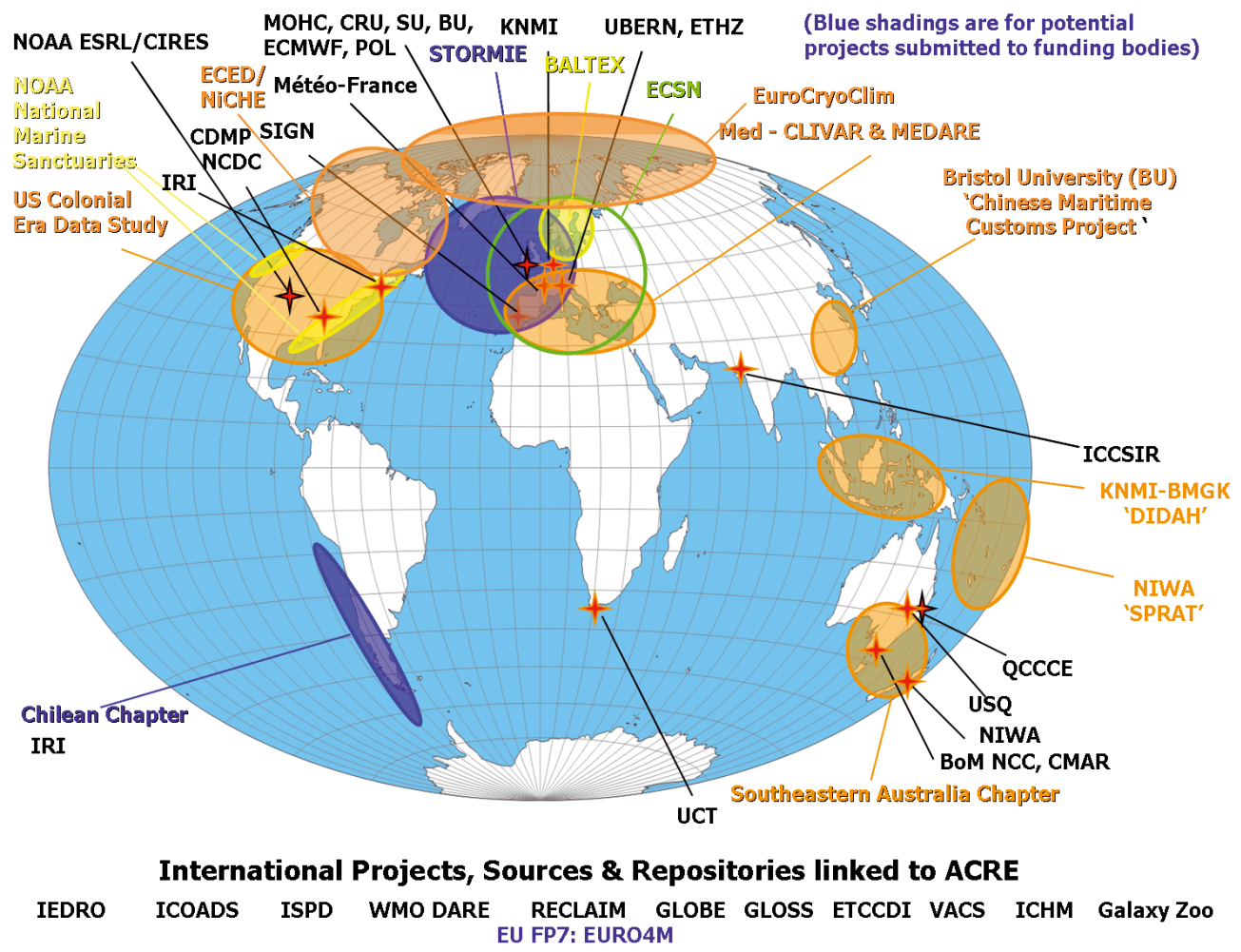

Fig. 7. The ACRE (Atmospheric Circulation Reconstructions over the Earth)linked projects, data sources and repositories from Allan (2009). Acronyms and abbreviations are given in Appendix Table A1. Orange: land-, Yellow: Marine-based projects; green: ECSN network; blue: defined in figure wide in order to support 4-dimensional (4D) weather reconstructions over the past 200$250 \mathrm{yr}$ at high-resolution $\left(2^{\circ} \times 2^{\circ}\right.$ latitude/ longitude and every $6 \mathrm{~h}$ ) using surface air pressure data and state-of-the-art scientific capacities. Fig. 7 illustrates the research centres, projects, data sources and repositories linked to ACRE (Allan 2009), and Fig. 8 shows the observed and currently accessible global climate data (upper panel) and what it is expected to be available after ACRE (lower panel) for surface and upper air weather data.

ACRE is working on the identification and collection of old weather observations and on imaging, digitising, analysing and ingesting the data into numerical weather prediction models for 4D reconstruction of global historical weather. The goal is a baseline of $4 \mathrm{D}$ weather reconstructions that can be tailored and downscaled to develop regional-to-local climate applications (e.g. agricultural, environmental, societal), to provide input on climate impacts and meteorological variables for biophysical and production models and to

Fig. 8. Observed climate at present (upper panel) and after ACRE efforts (lower panel) from Brohan (2009). Surface coverage values $=$ proportion of Earth's surface area
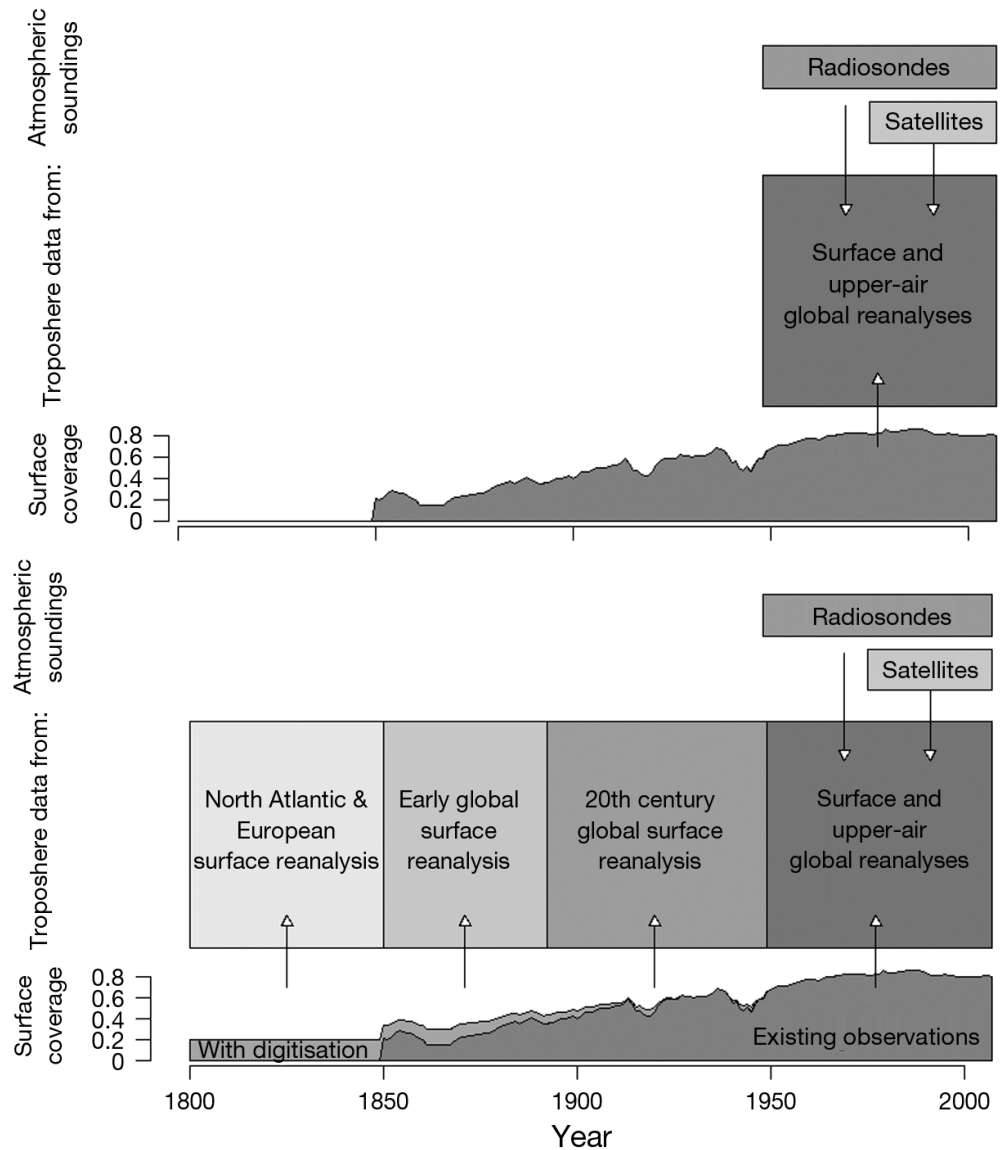
furnish an historical baseline of global reanalysis that can be employed to constrain global climate models (Compo et al. 2009).

\section{SUMMARY AND OUTLOOK}

In the current paper we have presented and discussed the importance of improving climate data availability all over the world. The examples used have emphasised the North Atlantic/European sectors, where many efforts have been undertaken to develop both long-term instrumental and proxy climate series. The long heritage of world climate data is still largely underexploited, due to different kinds of political, social and economic circumstances and degrees of technical and scientific development worldwide, which prevent some of the recorded data from being transferred into usable formats and risk their permanent loss. We have also attempted to provide some background on DARE activities worldwide. In particular, we have described the WMO/MEDARE and ACRE initiatives, with a focus on the usefulness of the data being recovered.

Some European countries (e.g. Finland, France, Germany, Holland, the United Kingdom) are digitising and homogenising their holdings and other countries, such as Australia, Canada, China, Japan and the United States, are also recovering/digitising their climate data as part of cooperative efforts (e.g. NMSs and academia). It will be important to engage other large countries, such as India and Brazil, and to foster interactions among NMSs, academia and interested scientists in a cooperative DARE effort.

It will also be important to secure more publicity for DARE's results and applications (e.g. assessments using newly recovered data should emphasise the initiative/project from which the data originate) and to raise awareness among policy-makers, stakeholders and climate data end-users concerning the essential need to undertake integrated DARE projects before using data in climatic studies.

It would also be useful to carry out DARE cost/ benefit analysis, to emphasise the minimal costs of DARE activities compared to the huge benefits possible through improved climate data availability once a climate record has been rescued and developed. Another crucial issue for DARE is the dissemination of recovered/developed climate data by improving the accessibility of the data. In this regard, the improvement of meteorological network interoperability will be extremely valuable in enhancing this accessibility. There is still a considerable need for further DARE activities, as many surface data have not yet been digitised.
Historical data stored in non-usable formats are hiding a valuable and unique climatic message, which can only be discovered and analysed after the data are transferred into digital formats. Increasing high-quality climate data availability and accessibility will confer huge societal benefits, through an improved knowledge of past climatic patterns that had high impacts on socio-economic systems (e.g. extreme weather events) and thus making our societies more climatically secure. Therefore, improved and more robust climate assessments are of paramount importance for today's and tomorrow's society, in order to better understand, predict and respond to global climate change. Carrying out DARE activities and high-quality climate data development is a debt that we owe to the meticulous and diligent work done by observers in the past, who conscientiously and rigorously measured our atmosphere. To bring these historical data into the 21st century is, therefore, not only important for better adaption within countries to the impacts of climate variability and change, but also to ensure that the painstaking atmospheric monitoring carried out in the past is not lost forever.

Acknowledgements. The authors are grateful to the EUfunded project EURO4M (European Reanalysis and Observations for Monitoring, FP7-SPACE-2009-1 Project No. 242093). M.B. also thanks WMO/CCl and WMO/WCDMP for their support.

\section{LITERATURE CITED}

Abbott PF (1986) Guidelines on the quality control of surface climatological data. WCP-85, WMO/TD No. 111, World Meteorological Organization, Geneva

Aguilar E, Auer I, Brunet M, Peterson TC, Wieringa J (2003) Guidelines on climate metadata and homogenization. WCDMP No. 53/WMO-TD No. 1186, World Meteorological Organization, Geneva. Available at: www.wmo. int/pages/prog/wcp/wcdmp/wcdmp_series/documents/WCDMP-53.pdf (accessed on 10 April 2010)

Allan R (2009) What ACRE will do? In: ACRE data and data visualisation meeting. Exeter Meeting, 15 September 2009. Available at: www.met-acre.org/meetings-and-workshops1/acre-data-and-visualisation-meeting (accessed on 10 April 2010)

Anonymous (2010) Editorial: data for eternity. Nat Geosci 3: 219

Ansell TJ, Jones PD, Allan RJ, Lister D and others (2006) Daily mean sea level pressure reconstructions for the European-North Atlantic region for the period 1850-2003. J Clim 19:2717-2742

Auer I, Bohm R, Jurkovic A, Lipa W and others (2007) Histalp-historical instrumental climatological surface time series of the greater alpine region. Int $\mathrm{J}$ Climatol $27: 17-46$

> Böhm R, Jones PD, Hiebl J, Frank D, Brunetti M, Maugeri M (2009) The early instrumental warm-bias: a solution for long central European temperature series 1760-2007. Clim Change 101:41-67 
Brandsma T, Van der Schrier G (2009) Indonesian data rescue. A Dutch-Indonesian initiative to rescue, digitize and disseminate data. In: ACRE data and data visualisation meeting. Exeter Meeting, 15 September 2009. Available at: www.met-acre.org/meetings-and-workshops-1/acre-dataand-visualisation-meeting (accessed on 10 April 2010)

Briffa KR (2000) Annual climate variability in the Holocene: interpreting the message of ancient trees. Quat Sci Rev 19: 87-105

Brohan P (2009) Why historical climate and weather observations matter? In: ACRE data and data visualisation meeting. Exeter Meeting, 15 September 2009. Available at: www.met-acre.org/meetings-and-workshops-1/acre-dataand-visualisation-meeting (accessed on 10 April 2010)

Brunet M (2009) The WMO Mediterranean Data Rescue (MEDARE) initiative. In: ACRE data and data visualisation meeting. Exeter Meeting, 15 September 2009. Available at: www.met-acre.org/meetings-and-workshops-1/acre-dataand-visualisation-meeting (accessed on 10 April 2010)

Brunet M, Kuglitsch FG (eds) (2008) Proceedings of the international workshop on rescue and digitization of climate records in the Mediterranean Basin. WCDMP No. 67/ WMO-TD No. 1432, World Meteorological Organization, Geneva

Brunet M, Jones PD, Sigró J, Saladié O and others (2007) Temporal and spatial temperature variability and change over Spain during 1850-2005. J Geophys Res D 112: D12117 doi:10.1029/2006JD008249

Brunet M, Saladié O, Jones P, Sigró J and others (2008) A case-study/guidance on the development of long-term daily adjusted temperature datasets. WCDMP No. 66/ WMO-TD No. 1425, World Meteorological Organization, Geneva

Compo GP, Smith C, Whitaker JS, Sardeshmukh PD (2009) Access and visualization of the 20th century reanalysis dataset. In: ACRE data and data visualisation meeting. Exeter Meeting, 15 September 2009. Available at: www.met-acre.org/meetings-and-workshops-1/acre-dataand-visualisation-meeting (accessed on 10 April 2010)

Daly C, Gibson WP, Doggett M, Smith J, Taylor G (2004) A probabilistic-spatial approach to the quality control of climate observations. In: Proceedings of the 14th AMS conference on applied climatology, 84th AMS annual meeting combined preprints. American Meteorological Society, Seattle, WA

Della-Marta PM, Luterbacher J, Weissenfluh H, Xoplaki E, Brunet M, Wanner H (2006) Summer heat waves over western Europe 1880-2003. Their changes and relationships to large scale forcings. Clim Dyn 29:251-275

Feng S, Hu Q, Qian W (2004) Quality control of daily meteorological data in China, 1951-2000: a new dataset. Int J Climatol 24:853-870

GCOS (Global Climate Observing System) (1996) Report of the Joint $\mathrm{CCl} / \mathrm{CBS}$ expert meeting on the GCOS surface network, Norwich, UK, 25-27 March 1996. GCOS-26, Geneva. Available at: www.wmo.ch/pages/prog/gcos/ Publications/gcos-26.pdf (accessed on 10 April 2010)

GCOS (1997) Initial selection of a GCOS surface networkFebruary 1997. GCOS-34, Geneva. Available at: www. wmo.ch/pages/prog/gcos/Publications/gcos-34.pdf (accessed on 10 April 2010)

GCOS (1998) Report of the OOPC/AOPC workshop on global sea surface temperature data sets, Palisades, NY, USA, 2-4 November 1998. GCOS-57, Geneva. Available at: www.wmo.ch/pages/prog/gcos/Publications/gcos-57.pdf (accessed on 10 April 2010)

GCOS (2001) Report of the GCOS regional workshop for east- ern and southern Africa on improving observing systems for climate, Kisumu, Kenya, 3-5 October 2001. GCOS-74, Geneva. Available at: www.wmo.ch/pages/prog/gcos/ Publications/gcos74_KisumuReport.pdf (accessed on 10 April 2010)

GCOS (2002) Report of the GCOS regional workshop for East and Southeast Asia on improving observing systems for climate, Singapore, 16-18 September 2002. GCOS-80, Geneva. Available at: www.wmo.ch/pages/prog/gcos/ Publications/gcos-80.pdf (accessed on 10 April 2010)

GCOS (2006) Report of the GCOS regional workshop for the Mediterranean Basin on improving observing systems for climate. Marrakech, Morocco, 22-24 November 2006. GCOS-106, Geneva. Available at: www.wmo.ch/pages/ prog/gcos/Publications/gcos-106eng.pdf (accessed on 10 April 2010)

Giorgi F (2006) Climate change hot-spots. Geophys Res Lett 33:L08707 doi: 10.1029/2006GL025734

Gloeden W (2009) Digitization of historical data at DWD. In: ACRE data and data visualisation meeting. Exeter Meeting, 16 September 2009. Available at: www.met-acre.org/ meetings-and-workshops-1/acre-data-and-visualisationmeeting (accessed on 10 April 2010)

Haylock MR, Goodess CM (2004) Interannual variability of European extreme winter rainfall and links with mean large-scale circulation. Int J Climatol 24:759-776

IPCC (Intergovernmental Panel on Climate Change) (2007) Climate change 2007: impacts, adaptation and vulnerability. In: Parry ML, Canziani OF, Palutikof JP, van der Linden PJ, Hanson CE (eds) Contribution of Working Group II to the 4th assessment report of the IPCC, Cambridge University Press, Cambridge

Jacobeit J, Rathmann J, Philipp A, Jones PD (2009) Central European precipitation and temperature extremes in relation to large-scale atmospheric circulation types. Meteorol Z 18:397-410

Jones PD (2008a) Benefits from undertaking data rescue activities. In: Brunet M, Kuglitsch FG (eds) Proceedings of the international workshop on rescue and digitization of climate records in the Mediterranean Basin. WCDMP No. 67/WMO-TD No. 1432. World Meteorological Organization, Geneva, p 9-14

Jones PD (2008b) Historical climatology - a state of the art review. Weather 63:181-186

Jones PD (2008c) Summary report of the WMO/WCP/ WCDMP MEDARE international workshop on rescue and digitization of climate records in the Mediterranean Basin. In: Brunet M, Kuglitsch FG (eds) Proceedings of the international workshop on rescue and digitization of climate records in the Mediterranean Basin. WCDMP No. 67/ WMO-TD No. 1432, World Meteorological, Organization, Geneva, $\mathrm{p}$ XV-XX

Jones PD, Moberg A, Osborn TJ, Briffa KR (2003) Surface climate responses to explosive volcanic eruptions seen in long European temperature records and mid-to-high latitude tree-ring density around the Northern Hemisphere. In: Robock A, Oppenheimer C (eds) Volcanism and the Earth's atmosphere. American Geophysical Union, Washington, DC, p 239-254

Klein Tank AMG, Können GP (2003) Trends in indices of daily temperature and precipitation extremes in Europe, 1946-99. J Clim 16:3665-3680

Klein Tank A, Wijngaard J, Van Engelen A (2002a) Climate of Europe. Assessment of observed daily temperature and precipitation extremes. European Climate Assessment \& Dataset project ECA\&D, KNMI, DeBilt

Klein Tank AMG, Wijngaard JB, Können GP, Böhm R and 
others (2002b) Daily dataset of 20th-century surface air temperature and precipitation series for the European Climate Assessment. Int J Climatol 22:1441-1453

Klingbjer P, Moberg A (2003) A composite monthly temperature record from Tornedalen in northern Sweden, 1802-2002. Int J Climatol 23:1465-1494

Mestre O (2008) A review of homogenisation procedures. In: Brunet M, Kuglitsch FG (eds) Proceedings of the international workshop on rescue and digitization of climate records in the Mediterranean Basin. WCDMP No. 67/ WMO-TD No. 1432, World Meteorological Organization, Geneva, p 41-46

Moberg A, Jones PD (2005) Trends in indices for extremes in daily temperature and precipitation in central and western Europe 1901-1999. Int J Climatol 25:1149-1171

Moberg A, Jones PD, Lister D, Walther A and others (2006) Indices for daily temperature and precipitation extremes in Europe analyzed for the period 1901-2000. J Geophys Res D 111:D22106 doi: 10.1029/2006JD007103

Peterson TC, Manton MJ (2008) Monitoring changes in climate extremes. A tale of international collaboration. Bull Am Meteorol Soc 89:1266-1271

Peterson TC, Easterling DR, Karl TR, Groisman P and others (1998a) Homogeneity adjustments of in situ atmospheric climate data: a review. Int J Climatol 18:1493-1517

Peterson TC, Vose R, Schmoyer R, Razuvaev V (1998b) Global historical climatology network (GHCN) quality control of monthly temperature data. Int J Climatol 18:1169-1179

Philipp A, Della-Marta PM, Jacobeit J, Fereday DR, Jones PD, Moberg A, Wanner H (2007) Long-term variability of daily North Atlantic-European pressure patterns since 1850 classified by simulated annealing clustering. J Clim 20: 4065-4095

Schär C, Vidale PL, Lüthi D, Frei Ch, Häberli Ch, Liniger MA, Appenzelle Ch (2004) The role of increasing temperature variability in European summer heatwaves. Nature 427: 332-336

Sciuto G, Bonaccorso B, Cancelliere A, Rossi G (2009) Quality control of daily rainfall data through neural networks. J Hydrol (Amst) 364:13-22

Stott PA, Stone DA, Allen MR (2004) Human contribution to the European heatwave of 2003. Nature 432:610-614

Szalai S, Szentimrey T (eds) (1996) Homogenization and qual- ity control in climatological databases, series of seminars. WCDMP-56 Series/WMO/Hungarian Met. Serv. Available at: www.wmo.int/pages/prog/wcp/wcdmp/wcdmp_series/ index_en.html (accessed on 10 April 2010)

Tan LS, Burton S, Crouthamel R, Van Engelen A and others (2004) Guidelines on climate data rescue. WCDMP No. 55, WMO-TD No. 1210, World Meteorological Organization, Geneva. Available at: www.wmo.int/pages/prog/wcp/ wcdmp/documents/WCDMP-55.pdf (accessed on 10 April 2010)

Trenberth KE, Jones PD, Ambenje P, Bojariu R and others (2007) Observations: surface and atmospheric climate change. In: Solomon S, Qin D, Manning M, Chen Z and others (eds) Climate change 2007: the physical science basis. Contribution of Working Group I to the 4th assessment report of the Intergovernmental Panel on Climate Change. Cambridge University Press, Cambridge

Udías A (2003) Searching the heavens and the earth: the history of Jesuit observatories. Kluwer Academic Publishers, Dordrecht

Vose RS, Schmoyer RL, Steurer PM, Peterson TC, Heim R, Karl TR, Eischeid J (1992) The global historical climatology network: long-term monthly temperature, precipitation, sea level pressure, and station pressure data. ORNL/CDIAC-53, NDP-041, Carbon Dioxide Information Analysis Center, Oak Ridge National Laboratory, Oak Ridge, TN

WMO (World Meteorological Organization) (1990) Report of the meeting on historical archival survey for climate history, Paris, 21-22 February 1990. WCDP No. 12, WMO-TD No. 372, WMO, Geneva

WMO (1996) Report on the status of the archival climate history survey (ARCHISS) project (prepared by Mr M. Baker). WCDMP No. 26, WMO-TD No. 776, WMO, Geneva

WMO (2008) Report of the meeting of the $\mathrm{CCl}$ expert team on the rescue, preservation and digitization of climate records. WCDMP No. 69, WMO-TD No. 1480, WMO, Geneva Available at: www.wmo.int/pages/prog/wcp/ wcdmp/wcdmp_series/documents/ET13reportFinal.pdf (accessed on 10 April 2010)

You J, Hubbard KG, Goddard S (2008) Comparison of methods for spatially estimating station temperatures in a quality control system. Int J Climatol 28:777-787 
Appendix: Table A1. Acronyms and abbreviations used in Fig. 7

\begin{tabular}{|c|c|}
\hline BALTEX & The Baltic Sea Experiment, EU \\
\hline BoM/NCC & Bureau of Meteorology/National Climatic Centre, Australia \\
\hline CDMP/NCDC & Climate Data Modernization Programme/National Climate Data Center, USA \\
\hline CMAR & CSIRO Marine and Atmospheric Research, Australia \\
\hline CRU & Climatic Research Unit, UK \\
\hline CSIRO & Commonwealth Scientific and Industrial Research Organisation, Australia \\
\hline ECED/NICHE & Early Canadian Environmental Data/Network in Canadian History \& Environment, Canada \\
\hline ECMWF & European Centre for Medium-Range Weather Forecasts, EU \\
\hline ECSN & European Climate Support Network, EU \\
\hline ETCCDI & Expert Team on Climate Change Detection and Indices, International \\
\hline ETZH & Eidgenössische Technische Hochschule Zürich, Switzerland \\
\hline EURO4M & European Reanalysis and Observations for Monitoring project \\
\hline EuroCryoClim & European Cryospheric Climate Monitoring System, EU \\
\hline GLOBE & Global Learning and Observation to Benefit the Environment, International \\
\hline GLOSS & The Global Sea Level Observing System, International \\
\hline ICCSIR & Indian Centre for Climate and Societal Impacts Research, India \\
\hline ICHM & International Commission on History of Meteorology, International \\
\hline ICOADS & International Comprehensive Ocean-Atmosphere Data Set, International \\
\hline IEDRO & International Environmental Data Rescue Organization, International \\
\hline IRI & International Research Institute, USA \\
\hline ISPD & The International Surface Pressure Databank, International \\
\hline KNMI & Koninklijk Nederlands Meteorologisch Instituut, Holland \\
\hline KNMI-BMGK “DIDAH" & KNMI- Badan Meteorologi Klimatologi dan Geofisika "DARE project", Holland-Indonesia \\
\hline MEDARE & Mediterranean Data Rescue Initiative, International \\
\hline Med-CLIVAR & Mediterranean Climate Variability, EU \\
\hline $\mathrm{MOHC}$ & Meteorological Office Hadley Centre, UK \\
\hline NIWA 'SPRAT' & $\begin{array}{l}\text { National Institute of Water \& Atmospheric Research 'The South Pacific Rainfall Atlas' Project, New } \\
\text { Zealand }\end{array}$ \\
\hline NOAA & National Oceanic and Atmospheric Administration, USA \\
\hline NOAA ESRL/CIRES & $\begin{array}{l}\text { NOAA Earth System Research Laboratory/Cooperative Institute for Research in Environmental } \\
\text { Sciences, USA }\end{array}$ \\
\hline QCCCE & Queensland Climate Change Centre of Excellence, Australia \\
\hline RECLAIM & Recovery of Logbooks and International Marine data, UK \\
\hline SIGN & Signatures of environmental change in the observations of the Geophysical Institutes, Portugal \\
\hline STORMIE & Storms in Europe project, EU \\
\hline SU & Sutherland University, UK \\
\hline UBERN & University of Bern, Switzerland \\
\hline USQ & University of Southern Queensland, Australia \\
\hline VACS & Variability of the African Climate System, International \\
\hline WMO DARE & World Meteorological Organization Data Rescue, International \\
\hline
\end{tabular}

